This paper reports a study into the effect of nanoclays on the water-resistance of the intumescent system ammonium polyphosphate/ melamine/pentaerythritol/titanium dioxide/ polymer (ethylene vinyl acetate (EVA) or styrene acrylate (SA).

It has been established that adding nanoclay to a coating based on ethylene vinyl acetate increases the fire resistance limit of a metal plate by $30 \%$, and to a coating based on styrene acrylate - by $50 \%$. At the same time, coatings that include the EVA polymer are characterized by greater fire-retardant efficiency and less water resistance than coatings containing the SA polymer.

It has been shown that intumescent coatings, regardless of the nature of the polymer, under the conditions of $80 \%$ humidity over 800 days their reduce fire-protective properties by an average of $10 \%$. The loss of coating fire resistance occurs due to the leaching of pentaerythritol, ammonium polyphosphate, and polymer degradation by hydrolysis. The admixtures of nanoclays with a high degree of exfoliation to the studied system create a barrier effect and maximize the chemical formulation of the intumescent coating. The fireproof properties of coatings with organically-modified montmorillonite admixtures are maintained or reduced to $5 \%$ under the conditions of $80 \%$ humidity over 800 days.

It has been determined that the direct effect of water on the coating over a period of more than 2 days leads to a significant decrease in the swelling coefficient of intumescent coatings, regardless of the content of a nanoclay admixture in their composition. At the same time, the half-decay period of coatings without nanoclay, calculated on the basis of solubility constant in water, is 0.5 days. For coatings, which include the admixtures of organicallymodified nanoclays, the half-decay period increases to 2 days.

The results reported in this paper could be recommended for designing water-proof fireresistant reactive-type nano-coatings with prolonged service life

Keyzords: fireprotection of steel, organicallymodified montmorillonite, intumescent coatings, ethylene vinyl acetate, styrene acrylate, fire resistance limit

$\square$

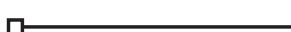

UDC $661.174 ; 667.6$

DOI: $10.15587 / 1729-4061.2021 .232822$

\section{COMPARING THE EFFECT OF NANOCLAYS ON THE WATER-RESISTANCE OF INTUMESCENT FIRE- RETARDANT COATINGS}

\author{
Liubov Vakhitova \\ $\mathrm{PhD}$ *
}

Kostyantyn Kalafat

Postgraduate Student**

Viktoria Plavan

Doctor of Technical Sciences**

Volodym y r Bessarabov Corresponding author

$\mathrm{PhD}$

Department of Pharmaceutical Industry***

E-mail: drvib500@gmail.com

$\mathbf{N}$ adezhda Taran

$\mathrm{PhD*}$

GIib Zagoriy

Doctor of Pharmaceutical Sciences Department of Pharmaceutical Industry***

*Department Research of Nucleophilic Reactions

L. M. Litvinenko Institute of

Physical-Organic Chemistry and

Coal Chemistry of the National Academy

of Sciences of Ukraine

Kharkivske shose str., 50, Kyiv, Ukraine, 02160

**Department of Applied Ecology,

Technology of Polymers and Chemical Fibers***

***Kyiv National University of Technologies and Design

Nemyrovycha-Danchenka str., 2, Kyiv, Ukraine, 01011
Received date: 26.03 .2021 Accepted date: 21.05 .2021 Published date: 18.06 .2021
How to Cite: Vakhitova, L., Kalafat, K., Plavan, V., Bessarabov, V., Taran, N., Zagoriy, G. (2021). Comparing the effect of nanoclays on the water-resistance of intumescent fire-retardant coatings. Eastern-European Journal of Enterprise Technologies, 3 (6 (111)), 59-70. doi: https://doi.org/10.15587/1729-4061.2021.232822

\section{Introduction}

Fire protection of steel structures by treating them with special fireproof materials is a mandatory measure and is regulated by national building standards. The most common and non-alternative fire protection means in many cases are the thin-layer polymeric intumescent (reactive) coatings consisting of ammonium polyphosphate (APP)/ melamine (MA)/pentaerythritol (PE) [1,2]. Despite their versatility, manufacturability in the application, aesthetic characteristics, intumescent-type coatings have a series of disadvantages. First of all, it is low atmosphere resistance [3] and resistance to aggressive environments [4], and, accordingly, a limited service life [5]. The authors of work [6], for example, found that after 30 years of natural aging under the climatic conditions of Italy, intumescent coatings lose their fire protection functions completely.

Therefore, studying the resistance of fire protection means against the influence of the external environment, moisture, weathering should be a necessary stage in devising the new technologies of reactive coatings. This information is important for predicting the service life of a fire protection coating in order to replace it in a timely manner and to ensure reliable and effective fire protection. 


\section{Literature review and problem statement}

One solution to the issue related to increasing the durability of fireproof coatings is the use of nano-structural flame retardants - nano oxides [7], nanoclays [8], boron nano compounds [9], and others. Many studies were published on improving the operational properties of the coating through the use of nanomaterials.

Paper [10] reports a study on the fire-protective effectiveness of an intumescent polyphosphate coating, modified by a mixture of phenol-formaldehyde bentonite nanocomposite, zinc nano oxide, and cobalt-ferrite layered double hydroxides $\left(\mathrm{LDH}_{\mathrm{s}}\right)$. It was established that the coating with nano-admixtures demonstrates increased fire resistance parameters in terms of corrosion impermeability. However, such a complex and multicomponent modification system is not considered economically feasible and applicable in the industrial production of fire protection means.

A detailed review of the issue related to the durability of coatings of the intumescent type with a composition of $\mathrm{APP} / \mathrm{MA} / \mathrm{PE}$ is given in [11]. It was shown that the slightest changes in chemical composition due to weathering or washing significantly reduce the fire-proof characteristics of these coatings. However, the review did not provide recommendations on methods and approaches to prolonging the service life of fire protection means.

Somewhat unexpected results of testing a fireproof coating for steel elements for artificial aging are reported in work [12]. It was established that the aging coefficient is $39.8 \%$ for the sample aged under weathering conditions for 480 hours. In turn, the sample, aged over 600 hours, almost does not show a fireproof effect. The likely reason for such conclusions is the inadequateness of the simulated conditions of artificial aging to the conditions under which fire protection means are typically operated [13].

Review [14] reports a study into the positive effect of nanomaterials on the fire-protective and operational properties of reactive-type coatings. Nanoparticles significantly increase the wear resistance, erosion resistance, and corrosion resistance of reactive coatings $[15,16]$. It is known that depending on the chemical nature, nano admixtures affect specific operational properties [14].

However, improving the intumescent coatings by nanomodification makes sense only if the use of nano admixtures does not compromise the effectiveness of fire protection. According to [14], the main directions of the effect of nanomaterials in intumescent compositions (IC) of APP/MA/PE formulation should be considered in the following areas:

- the catalysis or inhibition of chemical processes;

- the creation of barriers to oxygen access to the combustion and migration zone of output gases;

- participation in the processes of embryo formation and carbonization in the structure of the coke frame.

These hypotheses regarding the role of nano admixtures in IC are confirmed in the study of intercalated graphite [17], montmorillonite, sepiolite [18], titanium nano oxides [8]. It was established that nanoparticles contribute to the carbonization of IC components with the formation of a coke layer of increased strength and thermal stabilization. In turn, the circumstance that nano admixtures have a powerful barrier effect is undeniable, which prevents the construction of a heat-protective frame and negatively affects the swelling coefficient and the thermal insulation properties of the coke layer [19]. On the one hand, conflicting literary data should be regarded as a lack of research into the impact of IC nanomodifiers on fire-protective coating effectiveness. On the other hand, the multicomponent nature of an intumescent coating ( $\mathrm{APP} / \mathrm{MA} / \mathrm{PE} /$ polymer/pigment/ filler/flame retardant, etc.), the variability of its thermal destructiveness, the lack of the confirmed nano-dimensional structure of a nano admixture in some cases, etc. do not contribute to the construction of unified scientific approaches and theories.

It should be noted that the issues of the methodology for determining the lifetime of the intumescent-type coatings are open. This is primarily due to the lack of procedures for modeling the conditions of artificial aging for a coating. There are also no adequate criteria for determining the fire-protective properties of the coating after aging, followed by forecasting its service life $[4,5]$. National and international standards, for example [20], to some extent define methodological approaches to determining the durability of reactive coatings. However, the proposed tests [20] are time consuming and expensive. For a preliminary assessment of the resistance of a coating against the influence of external factors, it would suffice to determine the degree of maintaining the fire-protective efficiency under the conditions of high humidity. According to many researchers [3, 5, 21], it is the washing out of soluble components from IC by water that is the most common cause of the loss of fire-protective effect of reactive coatings. However, information about studies into the effects of water on the destruction of intumescent-type coatings is limited and not systematic. This applies, first of all, to investigating the dependence of coating stability under operating conditions with high humidity on the nature of the polymer component. There are also no generalizations regarding the role of nanoparticles present in fire protection means in increasing the operational characteristics and durability of the coating.

\section{The aim and objectives of the study}

The purpose of this work is to compare the effect of layered silicates (nanoclays) on water resistance and on a change in the fireproof efficiency of the intumescent system polyphosphate ammonium/melamine/pentaerythritol/titanium dioxide/polymer. This would make it possible to devise new approaches to the technology of reactive-type fire protection coatings with prolonged service life.

To accomplish the aim, the following tasks have been set:

- to determine an interrelation between the nature of nanoclays and the fireproof effectiveness of the coating;

- to study the kinetics of coating solubility in water when tested for static immersion;

- to investigate the effect of nanoclay structure on a change in the physical-chemical characteristics of the coating during operation under the conditions of $80 \%$ humidity.

\section{The study materials and methods}

\section{1. Materials and equipment used in the experiment}

We have used the following components of IC - ammonium polyphosphate Exolit AP 422 (Clariant, Germany), micronized pentaerythritol Charmor PM40 (Perstorp Holding AB, Sweden), melamine (Borealis Agrolinz Melamine $\mathrm{GmbH}$, Austria). Titanium dioxide, grade Ti- 
Pure R-902 (DuPont, USA), was used as a flame retardant and a fireproof coating pigment. As a polymer component, a copolymer of styrene with acrylate (SA), Pliolite AC80, manufactured by Omnova Solutions (USA), and polymer dispersion of the copolymer of ethylene with vinyl acetate (EVA), Mowilith LDM 1780 (Celanese Corporation, USA), were investigated.

The nanoclays manufactured by BYK Additives \& Instruments (Germany) are represented by layered silicates. Optigel WA - bentonite $\left.\mathrm{Si}_{8} \mathrm{Al}_{4} \mathrm{O}_{20}(\mathrm{OH})_{4} \cdot \mathrm{nH}_{2} \mathrm{O}\right)$. Garamite 7305 - a mixture of montmorillonite modified by benzalkonium, [M-nH $\left.\mathrm{n}_{2} \mathrm{O}\right]\left(\mathrm{Al}_{4-\mathrm{x}} \mathrm{Mg}_{\mathrm{x}}\right) \mathrm{Si}_{8} \mathrm{O}_{20}(\mathrm{OH})_{4}$, and sepiolite $\left.\mathrm{Mg}_{4}\left(\mathrm{Si}_{6} \mathrm{O}_{15}\right)(\mathrm{OH})_{2} \cdot 6 \mathrm{H}_{2} \mathrm{O}\right)$. Clayton $\mathrm{HY}$, montmorillonite modified by tall alkonium. Laponite EP, modified synthetic magnesium silicate, an analog of hectorite, whose formula is $\mathrm{CaO}_{3}\left(\mathrm{Cr}^{3}+, \mathrm{Mg}^{2+}, \mathrm{Fe}^{2+}\right)_{2}(\mathrm{Si}, \mathrm{Al})_{4} \mathrm{O}_{10}(\mathrm{OH})_{2} \cdot 4 \mathrm{H}_{2} \mathrm{O}$. The classification of nanoclays is based on the specifications by manufacturers.

To identify the composition of coatings and coke residues, methods of IR spectroscopy were used at the device Specord 75 IR; UV spectroscopy, at the Optizen POP spectrophotometer. The diffractometer DRON-2 was used for $\mathrm{X}$-ray phase analysis. We studied the rheological properties of the intumescent composition at the Brookfield DV-III rotary rheometer. The washing out of intumescent coating components was examined using the Vankel VK 7000 dissolving device.

Determining the swelling coefficient of intumescent compositions $\left(K, \mathrm{~cm}^{3} / \mathrm{g}\right)$ and the mass value of the coke residue (m, \%) was described in work [10].

\section{2. Preparation of intumescent compositions}

Intumescent compositions were prepared by mixing in the laboratory dissolver the components of the intumescent system: ammonium polyphosphate, pentaerythritol, melamine, titanium dioxide at a ratio of 3.0:1.1:1:0.7 (mass share), 3.6 mass shares of the SA polymer (in the form of $30 \%$ solution in xylol), or 2.2 mass shares of $50 \%$ EVA aqueous dispersion. The formulations of the studied intumescent compositions are given in Table 1.

We formed films from the intumescent composition by pouring it into a plastic mold measuring $30 \times 30 \times 1 \mathrm{~mm}$, which was dried for 7-10 days. After drying to a constant mass, the film sample was used for further research.

\section{3. Fire tests}

Fire tests of intumescent coatings in a mini furnace under the conditions of "standard fire". For fire tests, a steel plate measuring $300 \times 300 \times 5 \mathrm{~mm}$ was painted on one side with a primer GF-021 with an average thickness of $80 \pm 10 \mu \mathrm{m}$. An intumescent composition with an average thickness of $1.50 \pm 0.10 \mathrm{~mm}$ was applied to the plate. The thickness of the coatings was measured using the Qnix1500 magnetic thickness gauge. The plate was aged at room temperature for at least 20 days. The plate was then put in the upper hole of the mini furnace the size of $600 \times 600 \times 600 \mathrm{~mm}$ with the painted part towards the fire exposure. We carried out two parallel tests and determined the average temperature on the plate. The error of measurements did not exceed $10 \%$. Control over the conditions of the "standard fire" and temperature registration on the outside of the plate was carried out using the K-type thermocouples and the automated measuring and registering complex "Test-1".

Determining the fire resistance limits of steel plates after aging under humidity conditions. Steel plates with intumescent coatings were prepared as described above. The plates were put in an airtight desiccator at a constant relative humidity of about $80 \%$. Humidity conditions were created by the use of $23 \%$ sulfuric acid solution in water. The humidity in the desiccator was controlled by the hygrometer GM1360A.

After aging the plates in the desiccator for 300 days, and at room temperature for 10 days, we determined the limit of fire resistance under the conditions of "standard fire" in a mini furnace.

\section{4. Testing water-resistance of the coating}

Testing at static immersion in water. A sample of the IC film measuring $30 \times 30 \times 1 \mathrm{~mm}$ was immersed in a container with distilled water of $1 \mathrm{dm}^{3}$. After a certain period, the sample was removed from the water, moisture residues were carefully removed with filter paper, we aged the sample for 1 hour at a temperature of $40{ }^{\circ} \mathrm{C}$ and weighed it.

A mass change $(\Delta m, \%)$ for each sample of IC was calculated from the following formula:

$$
\Delta m=\frac{m_{0}-m_{e}}{m_{0}} \cdot 100
$$

where $m_{0}(\mathrm{~g})$ and $m_{\mathrm{e}}(\mathrm{g})$ are the mass of the film before and after immersion in water, respectively.

Formulation (mass share) of intumescent compositions

\begin{tabular}{|c|c|c|c|c|c|}
\hline \multirow{2}{*}{ IC No. } & \multirow{2}{*}{ Nanoclay $^{*}$} & \multirow{2}{*}{$\mathrm{APP} / \mathrm{MA} / \mathrm{PE} / \mathrm{TiO}_{2}$ mass share } & \multicolumn{2}{|c|}{ Polymer } & \multirow{2}{*}{ Brookfield viscosity, Pa·s } \\
\cline { 4 - 5 } & & & $\mathrm{EVA}$ mass share & SA, mass share & \\
\hline 1 & - & 1 & 0.37 & - & 6.4 \\
\hline 2 & Optigel WA & 1 & 0.37 & - & 13.2 \\
\hline 3 & Garamite 7305 & 1 & 0.37 & - & 12.1 \\
\hline 4 & Clayton HY & 1 & 0.37 & - & 11.4 \\
\hline 5 & Laponite EP & 1 & 0.37 & - & 18.3 \\
\hline 6 & - & 1 & - & 0.61 & 4.5 \\
\hline 7 & Optigel WA & 1 & - & 0.61 & 3.3 \\
\hline 8 & Garamite 7305 & 1 & - & 0.61 & 28.8 \\
\hline 9 & Clayton HY & 1 & - & 0.61 & 12.4 \\
\hline 10 & Laponite EP & 1 & - & 0.61 & \\
\hline
\end{tabular}

Note: *the content of nanoclay in the intumescent composition is 1\% (by weight) 
We carried out two parallel measurements of mass changes and determined the mean value. The error of measurements did not exceed $7 \%$.

Testing under the conditions of constant relative humidity of $80 \%$. 2 liters of $23 \%$ aqueous solution of sulfuric acid in water were placed in the desiccator with a capacity of $18.5 \mathrm{li}-$ ters. Above the surface of the solution, we placed the samples of films measuring $30 \times 30 \times 1 \mathrm{~mm}$. At certain intervals, the samples were extracted from the desiccator, aged for 1 hour at a temperature of $40{ }^{\circ} \mathrm{C}$, weighed, we then determined the swell coefficient. $K$ values were obtained from two parallel samples followed by determining the mean value. The error of measurements did not exceed $10 \%$.

Humidity in the desiccator was controlled by the hygrometer GM1360A.

Measuring the kinetics of dissolving an intumescent coating in water. A sample of the intumescent coating film of $30 \times 30 \times 1 \mathrm{~mm}$ was dried in a drying chamber at a temperature of $50{ }^{\circ} \mathrm{C}$ to a constant mass. We dissolved the samples in the device for dissolving Vankel VK 7000. The dissolution conditions are as follows: spindle rotation speed, 100rpm; distilled water, $300 \mathrm{ml}$; temperature, $25^{\circ} \mathrm{C}$; dissolving time, $1 \mathrm{~h}$. The weighted sample of the film was wrapped in filter paper, placed in a basket, we then enabled stirring. At certain intervals, a sample was taken from the water with a syringe filter to determine the amount of melamine phosphate (MP) by UV spectroscopy at wavelength $\lambda=210 \mathrm{~nm}$. Separate experiments have found that when dissolving the APP/ $\mathrm{MA} / \mathrm{PE} /$ polymer coating, melamine in water is present in the form of MP, as evidenced by a maximum absorption shift from $235 \mathrm{~nm}$ (melamine solution) to $210 \mathrm{~nm}$ (solution of melamine with polyphosphoric acid at a ratio of 1:3). Fig. 1 shows the dependence of MP concentration in the aqueous phase on the time of dissolution.

The determined concentrations of $M P$ were used to calculate the constant of dissolution of the intumescent coating $k_{S}\left(\mathrm{~s}^{-1}\right)$ from the following formula:

$$
k_{s}=\frac{1}{t} \ln \frac{[M P]_{\text {sat }}}{[M P]_{s a t}-[M P]},
$$

where $[M P]_{\text {sat }}$ and $[M P], \mathrm{M}^{-1}$ are the concentrations of $M P$ in saturated solution and at the time of sampling $t(\mathrm{~s})$.

\section{Results of studying the effect of nanoclays on the water-resistance of intumescent systems}

5. 1. Relationship between a nanoclay nature and the coating fireproof efficiency

Fireproof reactive coatings, whose compositions are given in Table 1, were tested in a mini furnace under a standard fire condition. The purpose of these tests was to determine the limit of fire resistance $(R)$ of the steel plate. The accepted limit of fire resistance was the time of warming up a steel plate to $500{ }^{\circ} \mathrm{C}$. The results of this experiment for ICs No. 1-10 are shown in Fig. 2. The content of nanoclays in all ICs was the same and equaled $1 \%$; the thickness of the coating on the plates was on average $1.5 \mathrm{~mm}$.

Comparing the data in Fig. 2, $a, b$ shows that coatings No. 1-5 (Fig. 2, a), which include the EVA polymer, are characterized by greater fire-resistance efficiency than coatings containing the SA polymer (No.6-10, Fig. 2, b), regardless of the presence of nanoclay in IC. This result is a consequence of the difference between the mechanisms of thermodestruction of vinyl acetate [22,23] and styrene acrylate [24] copolymers.

To quantify the structure of the thermal insulation layer, whose strength and thermal conductivity plays a decisive role in fire protection, it is advisable to use the swell coefficient $\left(K, \mathrm{~cm}^{3} / \mathrm{h}\right)[10]$.

Fig. 3 shows the dependence of $K$ values on the amount of nanoclay in IC Nos. 1-5 (Fig. 3, $a$ ) and Nos. 6-10 (Fig. 3, $b$ ). To carry out this experiment, the IC films the size of $30 \times 30 \times 1 \mathrm{~mm}$, which varied in nanoclay in terms of quantity and structure, were aged for 10 minutes at a temperature of $350{ }^{\circ} \mathrm{C}$. After cooling the samples, we determined a value of the swell coefficient $\left(K, \mathrm{~cm}^{3} / \mathrm{h}\right)$ as a share of the volume of coke obtained to the mass of the starting film.

The data in Fig. 3 demonstrate the determining effect of the amount of nanoclay on the thickness of the coke layer formed from IC. In turn, our results call into question the established opinion [19] that the optimal amount of nanoclay to ensure effective fire protection of IC is $3 \%$. It follows from the derived values $K$ (Fig. 3 ) that for the organically-modified montmorillonites Garamite 7305 and Clayton HY, a significant decrease in the swell coefficient occurs at the content of nanoclay at the level of $1 \%$.

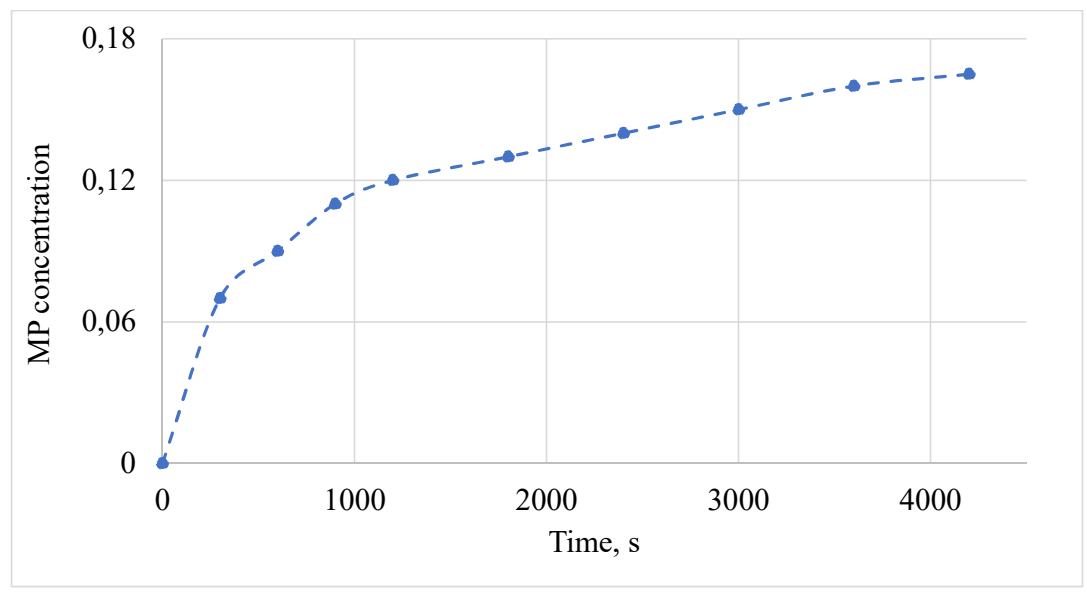

Fig. 1. Dependence of melamine phosphate concentration $\left(M P, \mathrm{M}^{-1}\right)$ in the aqueous phase of IC No. 10 (Table 1) on the time of dissolution (s) 


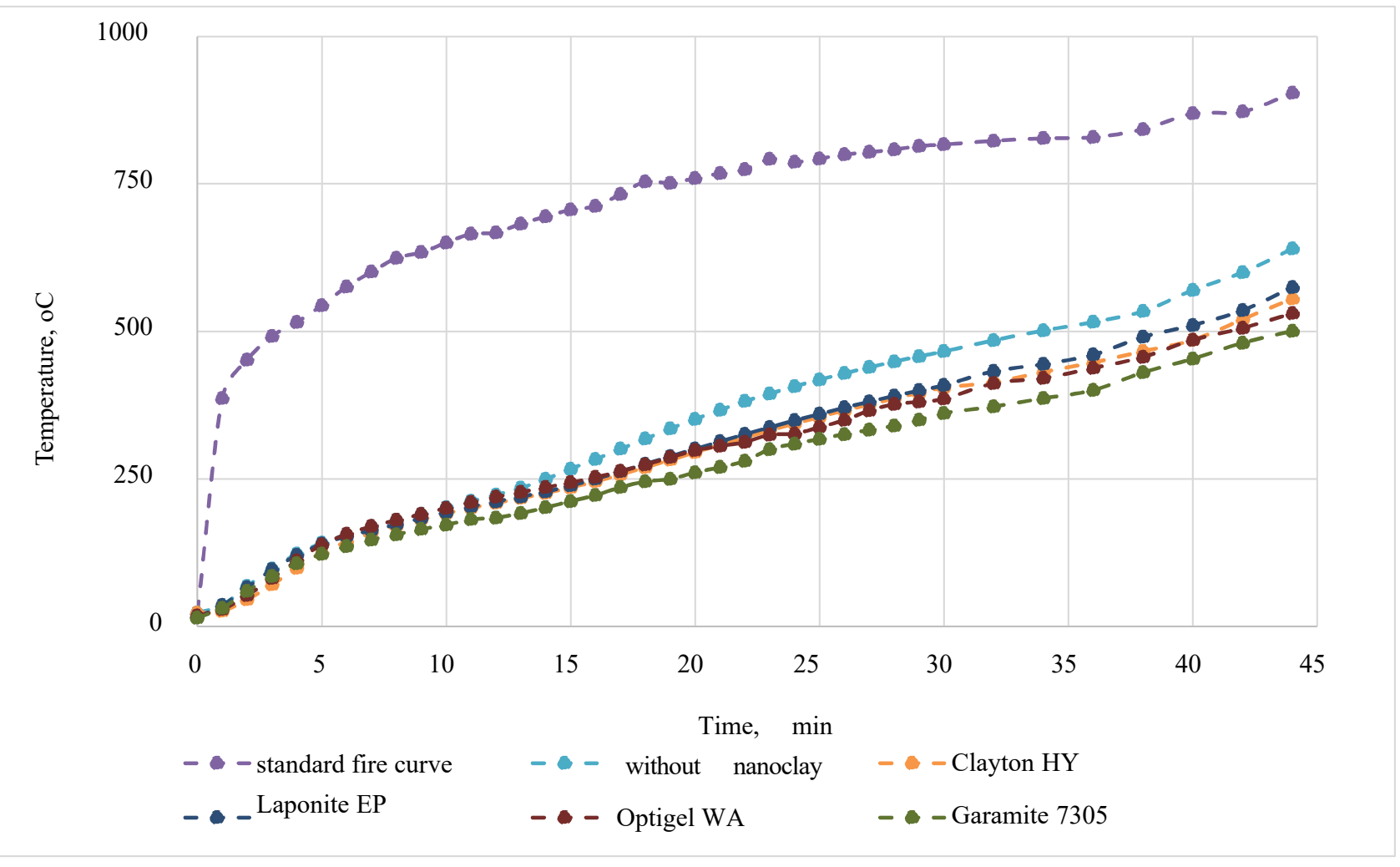

$a$

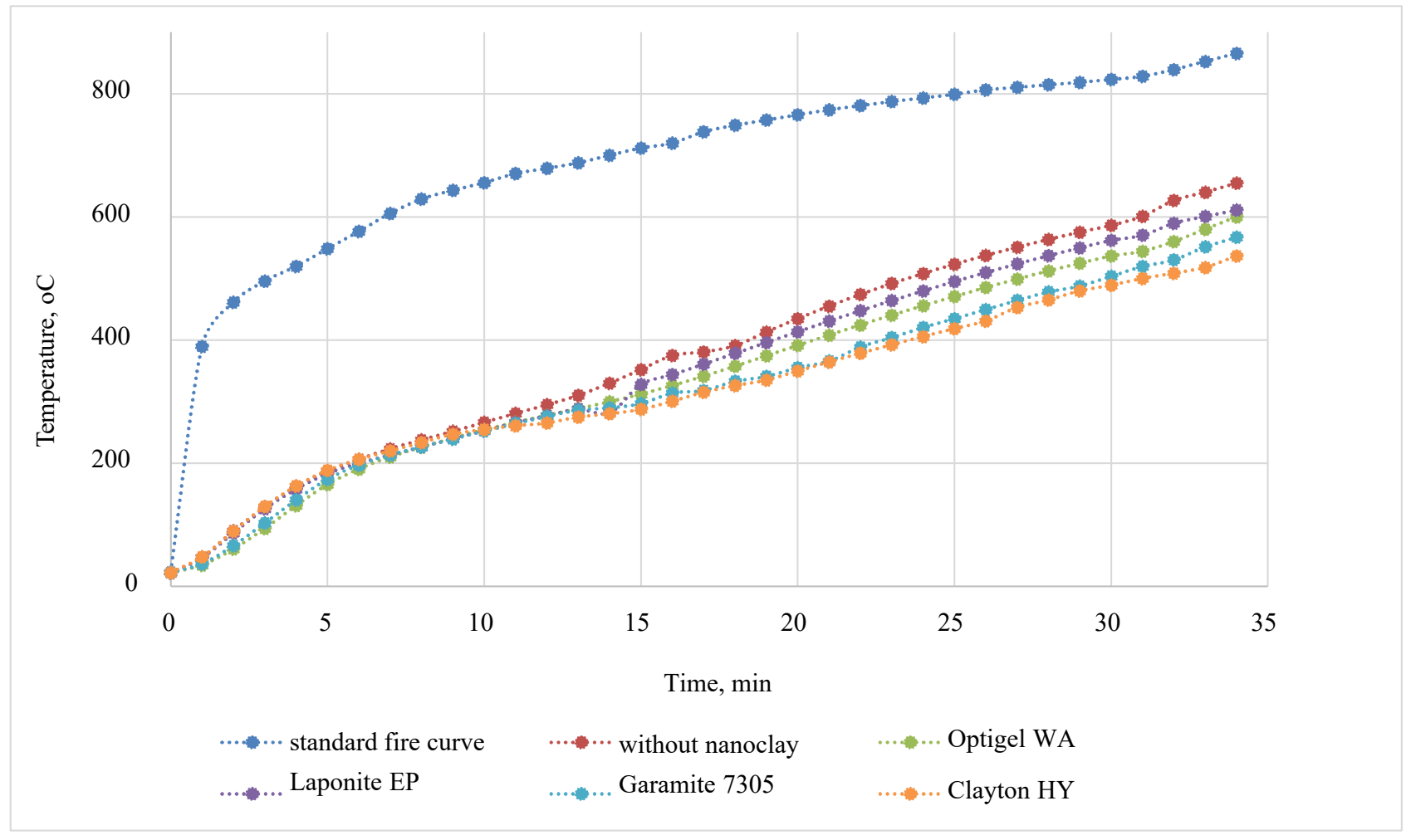

$b$

Fig. 2. Dependence of the temperature of metal plates $\left(T,{ }^{\circ} \mathrm{C}\right)$, protected by intumescent compositions, on the time of exposure to the flame ( $\mathrm{min})$ : $a-$ No. $1-5 ; b-$ No. $6-10$ 


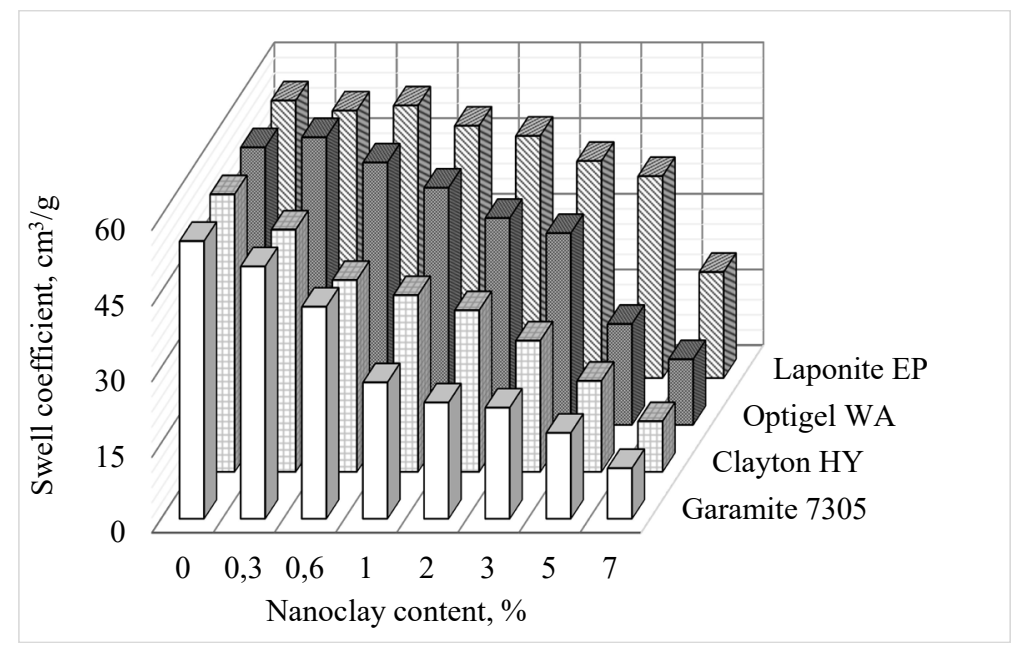

$a$

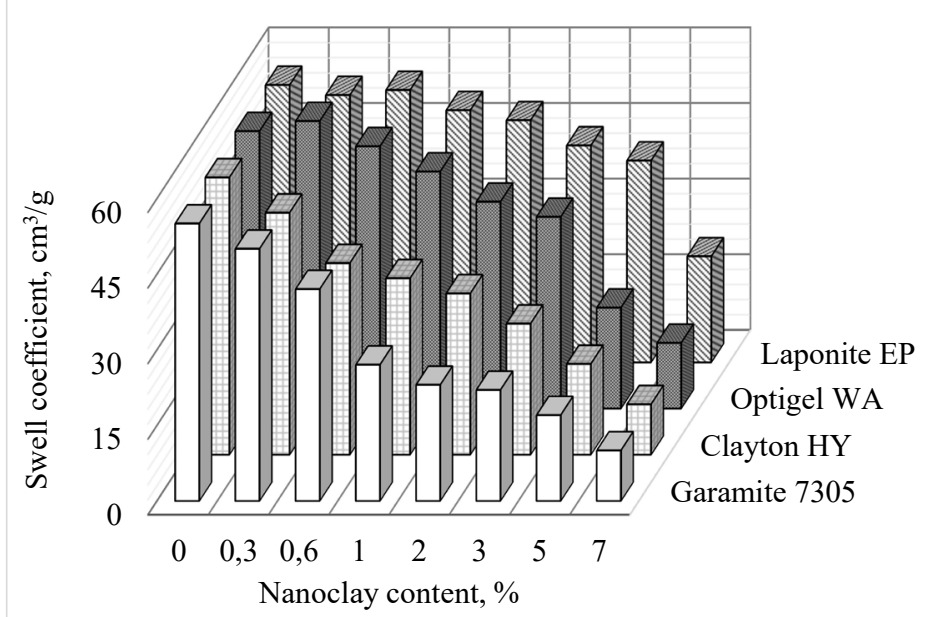

$b$

Fig. 3. Dependence of the swell coefficient $\left(K, \mathrm{~cm}^{3} / \mathrm{g}\right)$ of intumescent coatings on the content of nanoclay (\%): $a-$ No. $1-5 ; b-$ No. $6-10$

5. 2. The kinetics of coating solubility in water when tested for static immersion

This work employed two methods to determine the effect of water and air humidity on intumescent coatings:

- tests during static immersion;

- a prolonged exposure (800 days) to the constant relative humidity of $80 \%$.

The static immersion test was used to assess the effect of water on the preservation of intumescent properties by thin-film coatings No. $1-10$ with a nanoclay content of $1 \%$. The data in Fig. 4 demonstrate the differences in weight change curves between the IC samples containing the EVA polymer (No. 1-5, Fig. 4, $a$ ) and those based on SA (No. 6-10, Fig. 4, $b$ ).

All tested IC, regardless of the polymer component, show the same type of change in their mass when immersed in water. First, the mass of the sample increases due to the sorption of water by the coating, then there is a decrease in the mass due to the dissolution of the coating and the washing out of IC components (Fig. 4).

Table 2 gives the parameters that characterize the effect of nanoclays on the dissolution of intumescent coatings No.1-10 in water: the loss of sample weight after 15 days $-\Delta m_{15}$; the start time of the sample dissolution $-t_{s}$. There are also data on the dynamics of change in the swell coefficient $\left(K, \mathrm{~cm}^{3} / \mathrm{h}\right)$ during the entire process and the values of constants of the dissolution of an intumescent coating $k_{s}\left(\mathrm{~s}^{-1}\right)$.

Table 2

Test results for ICs No. 1-10 at the static immersion in water

\begin{tabular}{|c|c|c|c|c|c|c|c|c|}
\hline \multirow{2}{*}{$\begin{array}{c}\text { IC } \\
\text { No. }\end{array}$} & \multirow{2}{*}{$\Delta m_{15}, \%$} & \multirow{2}{*}{$t_{s}$, day } & \multicolumn{4}{|c|}{$K, \mathrm{~cm}^{3} / \mathrm{g}$} & \multirow{2}{*}{$k_{s} \cdot 10^{4}, \mathrm{~s}^{-1}$} & \multirow{2}{*}{$\tau_{1 / 2}$, day } \\
\hline & & & 0 day & 2 days & 6 days & 15 days & & \\
\hline 1 & 27 & 4 & 51 & 48 & 32 & 3 & 7.84 & 0.6 \\
\hline 2 & 16 & 8 & 49 & 52 & 38 & 9 & 3.21 & 1.5 \\
\hline 3 & 10 & 10 & 48 & 50 & 42 & 13 & 2.91 & 1.7 \\
\hline 4 & 7 & 10 & 45 & 45 & 39 & 14 & 2.82 & 1.7 \\
\hline 5 & 22 & 8 & 41 & 44 & 31 & 8 & 5.42 & 0.9 \\
\hline 6 & 20 & 6 & 55 & 53 & 34 & 5 & 6.62 & 0.7 \\
\hline 7 & 14 & 8 & 47 & 49 & 28 & 10 & 5.03 & 1.0 \\
\hline 8 & 7 & 10 & 27 & 31 & 25 & 11 & 2.60 & 1.9 \\
\hline 9 & 9 & 10 & 35 & 38 & 30 & 12 & 2.54 & 1.9 \\
\hline 10 & 16 & 8 & 50 & 46 & 31 & 10 & 6.31 & 0.8 \\
\hline
\end{tabular}

Note: * the content of nanoclay in the system is $1 \%$ 


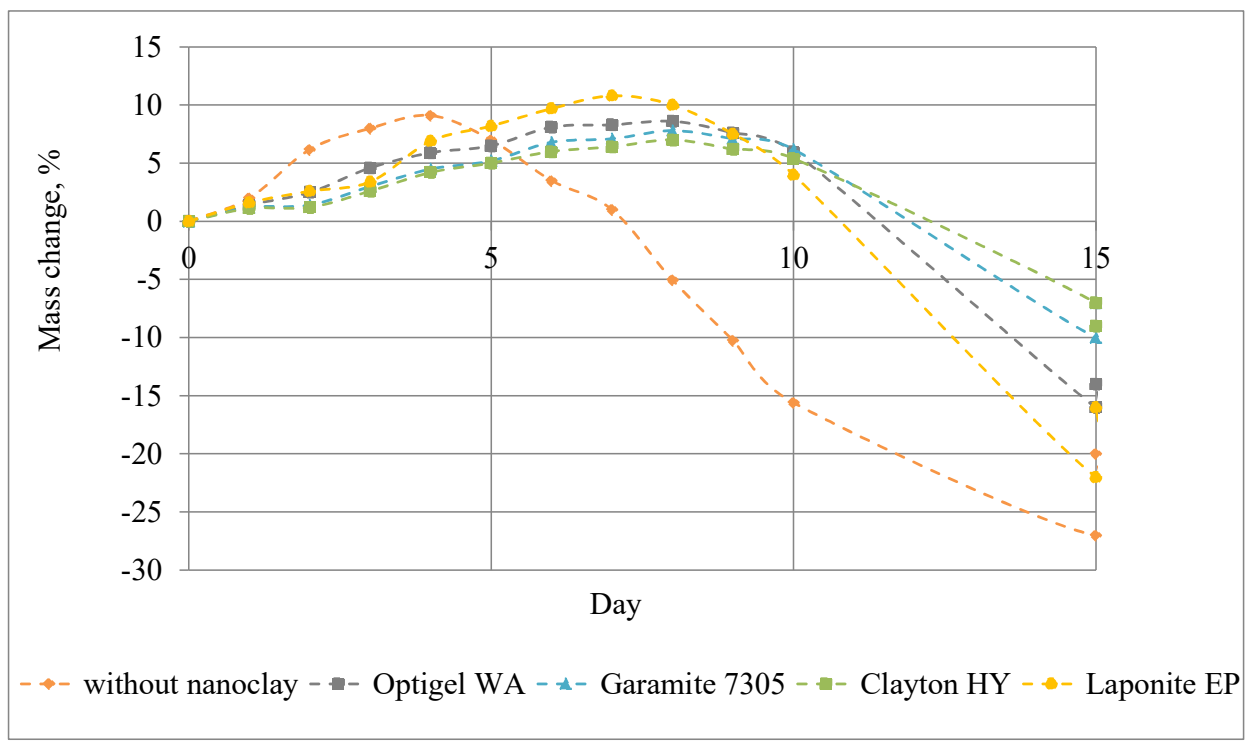

$a$

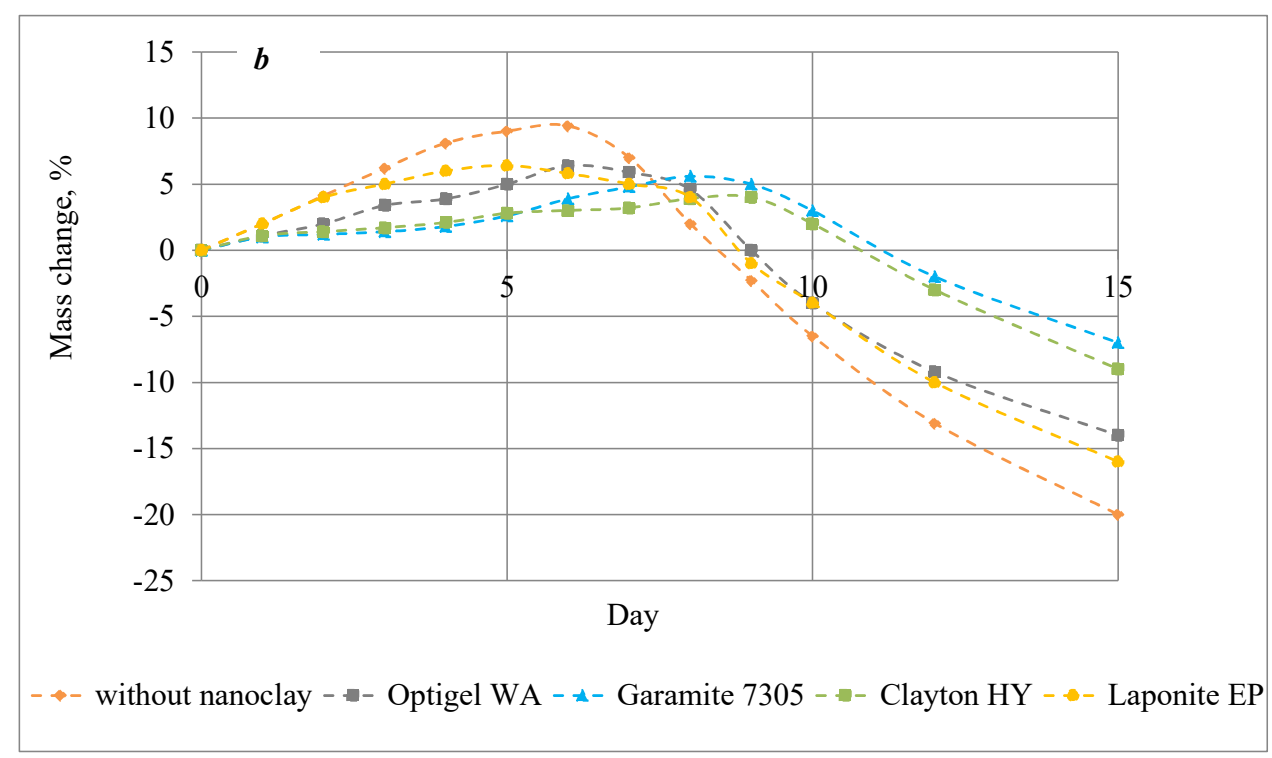

$b$

Fig. 4. Change in the mass $(\Delta m, \%)$ of intumescent coatings over time (24 hours) at the static immersion in water: $a-$ No. $1-5 ; b-$ No. $6-10$

With all the differences in parameters on the effects of water on the ICs formed by vinyl acetate (No. 1-5, Table 2) and styrene acrylate (No. 6-10, Table 2) polymers, the effect of nanoclays has a general tendency to preserve the chemical composition of the coating. The resistance to the static action of water decreases in a series: Garamite 7305 Clayton HY>Optigel WA>Laponite EP.

5. 3. Effect of nanoclay structure on a change in the physical-chemical characteristics of a coating during operation under the conditions of $80 \%$ humidity

Fig. 5 demonstrates the dynamics of change in the swell coefficient $\mathrm{K}$ for the samples of intumescent coatings without nanoclay (No. 1,6) and with an admixture of Garamite 7305 in the amount of $1 \%($ No. 3,8$)$ with prolonged exposure to a relative humidity of $80 \%$.
After aging the samples for 800 days, there is a decrease in the value of $\mathrm{K}$ compared to the original compositions: for IC No. 1 and No. 6 , by 33 and $30 \%$, and for IC No. 3 and No. 8 , by 16 and $14 \%$, respectively.

The results of the experiment to determine a change in the mass of IC samples for 800 days at a relative humidity of $80 \%$ are given in Table 3 .

The degree of decrease in the value of $K$, as well as data on the reduction of the mass of samples within 800 days, indicate a slight change in the chemical composition of the coating during the tests.

Results from fire tests of the steel plates protected by intumescent coatings No. 1-10, after aging at a relative humidity of $80 \%$ for 300 days, dependent on the time of flame action are given in Table 4 . 


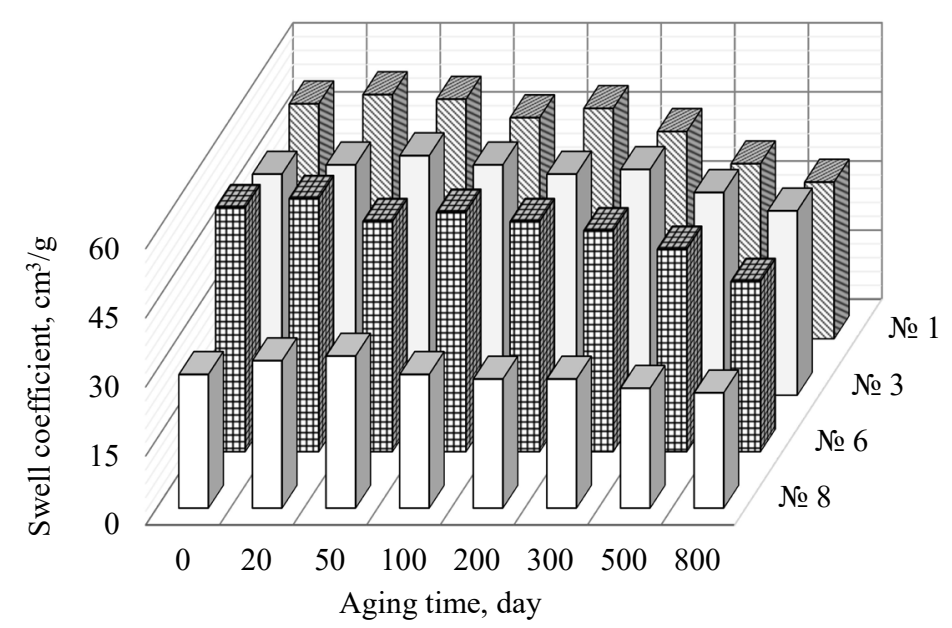

Fig. 5. Dependence of the swell coefficient $\left(\mathrm{K}, \mathrm{cm}^{3} / \mathrm{h}\right)$ of intumescent coatings on aging time (day) at a relative humidity of $80 \%$

Table 3

Table 4

Change in the weight $(\Delta m, \%)$ of samples of intumescent coatings after aging at a relative humidity of $80 \%$

\begin{tabular}{|c|c|c|c|c|}
\hline \multirow{2}{*}{$\begin{array}{c}\text { Aging time, } \\
\text { day }\end{array}$} & \multicolumn{4}{|c|}{$m, \%^{*}$} \\
\cline { 2 - 5 } & No. 1 & No. 3 & No. 6 & No. 8 \\
\hline 20 & +3.23 & +1.85 & +2.33 & +1.45 \\
\hline 50 & +5.08 & +2.29 & +3.18 & +1.97 \\
\hline 100 & +5.32 & +2.45 & +4.32 & +1.05 \\
\hline 200 & -0.34 & +0.61 & +0.24 & +0.42 \\
\hline 300 & -3.31 & -0.53 & -0.42 & -0.21 \\
\hline 500 & -5.02 & -3.06 & -3.15 & -2.28 \\
\hline 800 & -5.42 & -3.54 & -4.84 & -3.09 \\
\hline
\end{tabular}

Note: * “+”- weight gain; “-”- weight reduction

Fig. 6 shows the dependence of the swell coefficient $K$ of intumescent coatings on the viscosity of the initial fireproof paints No. 1-10.
Fire resistance limit of intumescent compositions No. 1-10 before $(R)$ and after $\left(R_{1}\right)$ aging at a relative air humidity of $80 \%$ for 300 days

\begin{tabular}{|c|c|c|c|c|c|c|c|c|c|c|}
\hline IC No. & 1 & 2 & 3 & 4 & 5 & 6 & 7 & 8 & 9 & 10 \\
\hline $\begin{array}{c}\text { Fire resis- } \\
\text { tance limit } \\
(R), \text { min }\end{array}$ & 34 & 41 & 44 & 39 & 37 & 22 & 27 & 29 & 32 & 25 \\
\hline $\begin{array}{c}\text { Fire resis- } \\
\text { tance limit } \\
\left(R_{1}\right), \text { min }\end{array}$ & 30 & 38 & 44 & 37 & 33 & 20 & 25 & 28 & 31 & 23 \\
\hline$\Delta R, \%$ & 12 & 7 & 0 & 5 & 11 & 9 & 7 & 3 & 3 & 8 \\
\hline
\end{tabular}

These results indicate a significant impact of the nanoclay structure at the coating formation stage, both at the stage of obtaining fireproof material and during operation in terms of resistance to external factors.

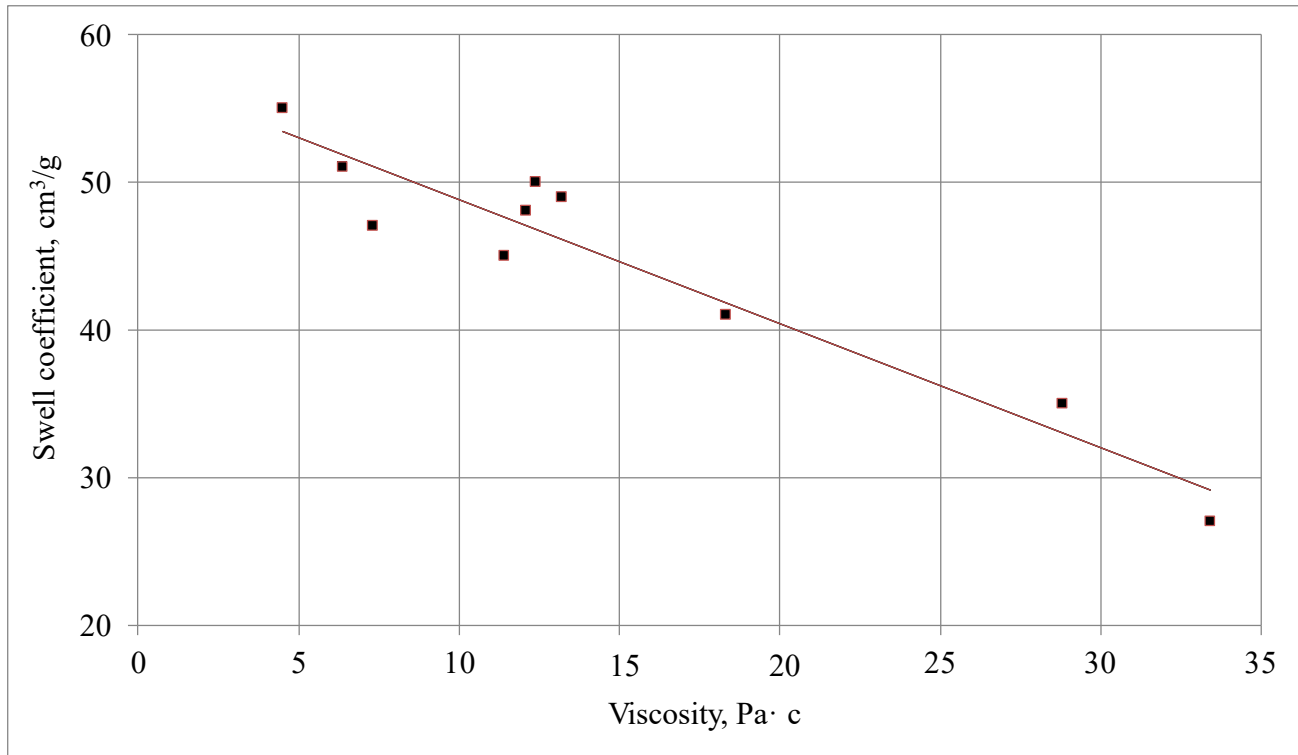

Fig. 6. Dependence of swell coefficient $\left(K, \mathrm{~cm}^{3} / \mathrm{h}\right)$ on the viscosity $(\mathrm{Pa} \cdot \mathrm{s})$ of intumescent compositions No. 1-10 


\section{Discussion of results of studying the effect of nanoclays on the water resistance and fireproof efficacy of intumescent coatings}

\section{1. Fireproof efficiency of an intumescent system}

The dependences of the temperature of steel plates protected by intumescent coatings No. 1-10 on the time of flame action (Fig. 2) demonstrated in all cases an increase in the limit of fire resistance ( $R$, Table 4$)$ when nanoclays are added to ICs.

It should be noted that the coatings based on the SA polymer (No. 7-10) are more sensitive to the effect of the nano admixture: the fire resistance of IC No. 9 (with Clayton HY, $R=32 \mathrm{~min}$, Table 4 ) is $50 \%$ larger than the fire resistance of IC, which does not contain nanoclay (No. 1, $R=22 \mathrm{~min}$, Table 2 ). For IC with the polymer EVA, the analogous difference between the fire resistance of systems No. 3 (with Garamite 7305, $R=44$ min, Table 2) and No. 1 (without nanoclay, $R=34 \mathrm{~min}$, Table 2 ) is $30 \%$. The main reason for the positive effect of nanoclays on the thermal resistance and fire-protective efficiency of IC is the structuring of the thermal insulation layer with the introduction of metal and silicon atoms into the polymer coke residue $[10,23]$. It is the presence of metalloid and silicon structures in the thermal insulation layer that leads to a slowdown in its thermal destruction in the temperature range of $500-700{ }^{\circ} \mathrm{C}[7,8]$.

The nature of change in $K$ in the presence of nanoclays in IC (Fig. 3) demonstrates a significant dependence not only on the concentration and nature of the nanoclay used but also on the structure of the polymer. If we consider the magnitude of IC swelling as the determining factor of the fire-protective efficiency of a reactive coating, then the results in Fig. 2, 3 allow us to highlight some general trends in the impact of the quantity and structure of nanoclays:

- for EVA-based IC (Fig. 3, $a$ ), the admixtures of Optigel WA, Clayton HY and Garamite 7305 are effective in the amount of up to $2 \%$ (optimally, $0.3 \%$ ), as well as the synthetic hectorite Laponite EP in the amount of up to $0.6 \%$ (optimally, $0.3 \%$ );

- for SA-based IC (Fig. 3, b), the organically-modified clays Clayton HY and Garamite 7305 provide relative preservation of $\mathrm{K}$ at nanoclay concentration of up to $0.3 \%$, Laponite EP - to $5 \%$, and Optigel WA - to $3 \%$.

This study does not examine the mechanisms behind the effect of nanoclays on multiple aspects of fire protection. However, our results make it possible to determine the relationship between the swell coefficient $\mathrm{K}$ and the degree of distribution of the nano admixture in an intumescent composition. Table 1 gives the values of viscosity (Pa.s) for intumescent compositions No.1-10, which could be considered as a measure of the distribution of nanoclay throughout the volume of IC, and, accordingly, the degree of structuring of the coating and the coke layer formed from it.

The results reported here can be interpreted in terms of increasing the contribution of the barrier effect of nanoclay in systems with high viscosity. Such systems are characterized by a large extent of dispersing and achieving the exfoliated state of nanoclays in the system. Multiple layers of dispersed silicates are an obstacle to the release of gases from the intumescent coating, and, accordingly, lead to a decrease in the swell coefficient. It is obvious that it is the ability of nanoclays to exfoliate in IC that determines the above-observed dependences of the fire-protective efficiency of IC both on the nature of the applied layered silicate and its quantity.

\section{2. Destruction of a fireproof coating under condi-} tions of static immersion

Comparing the results shown in Fig. 4 reveals two main conclusions:

- SA polymer-based ICs are more resistant to water than similar EVA polymer-based ICs. Over 15 days of immersion in water, the sample of IC No. 1 (containing EVA) loses $27 \%$ of its original mass. At the same time, the loss of mass by sample No. 6 (containing SA) is $20 \%$;

- the admixtures of nanoclay in IC reduce by $3-4$ times the solubility of the intumescent coating in water. Moreover, the loss of mass by samples depends on the structure of the introduced nanoclay.

The results obtained during the tests of ICs No. 1-10 at the static immersion in water are quantitatively consistent with the constants of dissolution of intumescent coating $k_{s}\left(\mathrm{~s}^{-1}\right)$ determined from formula (2). The $k_{s}$ values make it possible to predict the half-decay period $\left(\tau_{1 / 2}\right.$, day) of the examined ICs (Table 2).

The above calculations lead to the conclusion that for both types of polymers, the greatest resistance to water is detected by IC with organically-modified bentonites - $\mathrm{Ga}$ ramite 7305 and Clayton HY. This behavior of nanoclays to some extent contradicts the established recommendations for the use of nanoclays to control the rheological properties of paints and varnishes. As a rule, for water-dispersion paints (No. 1-5), hydrophilic silicates (for example, Optigel WA, Laponite EP) are considered the most optimal admixtures. At the same time, for paints containing organic solvents (No.6-10), hydrophobic organically-modified nanoclays such as Garamite 7305 and Clayton HY should be effective.

The likely reason for such inconsistencies is the ability of nanoclays to exfoliate in IC, which depends on the size of the basal interval $d$ - the interlayer distance between the silicate mono plates of nanoclays. According to X-ray phase analysis, the values of $\mathrm{d}$ decrease in the series $\mathrm{Ga}$ ramite $7305(2.37 \mathrm{~nm})>$ Clayton $\mathrm{HY}(2.24 \mathrm{~nm})>$ Laponite EP $(1.41 \mathrm{~nm})>$ Optigel WA $(1.21 \mathrm{~nm})$. Given that the studied ICs are highly filled compositions, we can assume that the polar properties of the medium (water or organic solvent) in such compositions would be partially neutralized. Therefore, it is the value of basal intervals, rather than the chemical nature of the nanoclay, that plays a decisive role in the degree of distribution (exfoliation) of the nano component in the volume of paint and varnish material.

The conclusions of this part of this study, despite the above generalizations, make it possible to emphasize the importance of the individual selection of the nanoclay structure in accordance with the nature of the polymer and the type of IC.

6. 3. Change in the fireproof coating efficiency under conditions of $80 \%$ humidity

It is known that intumescent coatings of the reactive type (except for epoxy and polyurethane) are recommended for use in closed premises with fluctuations in the relative humidity to $70 \%$. When applying a protective layer, the recommended air humidity can be up to $80 \%$. Therefore, the results of tests when immersed in water should be 
considered only as a demonstration of the positive effect of nanoclays on the water-resistance of an intumescent coating under extreme conditions.

The loss of mass by the coatings $(\Delta m, \%)$ based on EVA (No. 1, 3, Table 3) over 800 days of sample aging under the conditions of $80 \%$ humidity slightly exceeds similar values for SA-based coatings (No. 6, 8, Table 3). The maximum values of $\Delta m$ in the experiment are on average $5 \%$. At the same time, for both compositions, the presence of nanoclay in the coatings (No. 3, 8, Table 3 ) reduces weight loss by an average of $35 \%$ compared to coatings No. 1,6 . The decrease in mass associated with the washing out of coating components is observed after 200 days of aging the samples that do not contain nanoclay, and after 300 days for samples that include nanoclay.

Determining the limit of fire resistance of steel plates $\left(R_{1}\right.$, Table 4$)$ after aging under the air humidity conditions of $80 \%$ for 300 days is consistent with the data shown in Fig. 5 and Table 3. In a general case, the presence of nanoclays in IC increases the fireproof properties of the coating by $5-10 \%$

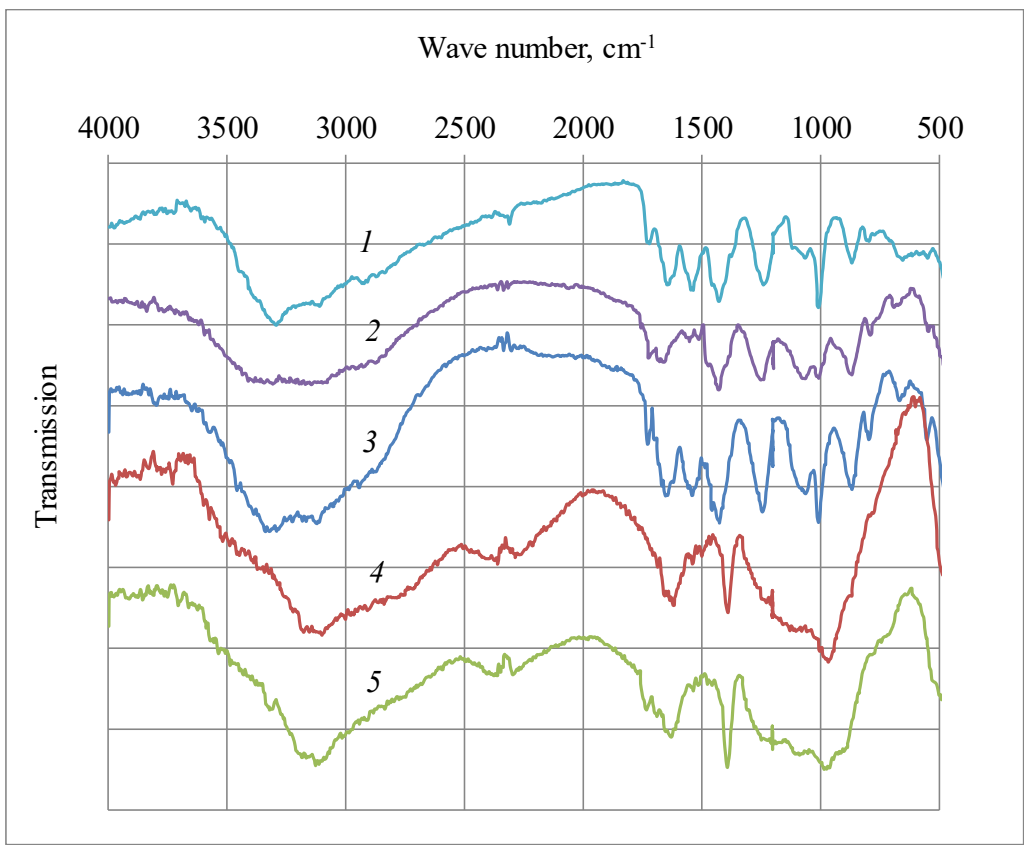

Fig. 7. IC IR-spectra after water resistance tests: 1 - IC No. 1; 2 - IC No. 1; 3 - IC No. 3 after exposure to $80 \%$ humidity for 800 days; 4 - IC No. 1; 5 - IC No. 3 after immersion in water for 15 days compared to IC without nanoclay. The degree of change in the fire-resistant limit $\left(\Delta R=\left(R / R_{1} \times 100, \%\right.\right.$, Table 3$)$ depends on the chemical nature of the nanoclay. When adding the organically-modified clays Garamite 7305 and Clayton $H Y$, the reduction of fire-retardant efficiency $\Delta R$ after exposure to moisture is from 0 (No. 4, Table 3 ) to $6 \%$ (No. 9 , Table 3). In turn, the admixtures of the clay Laponite EP (No. 5, 10, Table 3) provide a decrease in the parameter $R$, compared to IC No. 1 and No. 6 without nanoclays. The simplest explanation for such differences in the effect of nanoclays on the fire-protective effectiveness of IC after exposure to moisture is the manifestation of a barrier effect, which, as shown above, depends on the individual structure of the nanoclay. The greater the ability to the exfoliation and distribution of nanoclay, the greater its barrier properties appear, creating obstacles to the washing out of components from the intumescent coating.

An example of IC No. 3, which demonstrated the best result in maintaining the value of $R$ (No. 3, Table 3), was used to study the chemical composition of samples at the end of water resistance tests. Fig. 7 shows the IC No. 3 IR-spectra before (spectrum 1, Fig. 7) and after exposure to $80 \%$ humidity for 800 days (spectra 2, 3, Fig. 7), as well as after immersion in water for 15 days (spectra 4, 5, Fig. 7). We identified the chemical composition of IC according to the absorption bands typical of the APP/MA/PE/EVA mixture.

Spectrum 1 in Fig. 7 (IC No. 1 before testing) contains characteristic absorption bands: $2,880-2,950 \mathrm{~cm}^{-1}$ the valence fluctuations of - $\mathrm{CH}-,-\mathrm{CH}_{2}$ groups in the polymers EVA and PE; the band of $1,730-1,720 \mathrm{~cm}^{-1}$ corresponds to the carbonyl group of the polymer; the band of $3,321 \mathrm{~cm}^{-1}$ belongs to the $\mathrm{O}-\mathrm{N}$ group in $\mathrm{PE}$, the bands of $3,155 \mathrm{~cm}^{-1}$ and $1,650 \mathrm{~cm}^{-1}$ indicate the N-H group, and the band of $1,435 \mathrm{~cm}^{-1}$ - a CN bond in MA; the band of $1,247 \mathrm{~cm}^{-1}$ corresponds to the group $\mathrm{P}=\mathrm{O}$, and the bands of $1,070 \mathrm{~cm}^{-1}$ and $1,016 \mathrm{~cm}^{-1}$ belong to the P-O-P bond of ammonium polyphosphate.

Comparing spectrum 1 (Fig. 7) to the spectrum of IC No. 3 after exposure for 800 days at a relative humidity of $80 \%$ (3, Fig. 7) shows that the effects of moisture practically did not change the chemical structure of IC No. 3 that included the Garamite 7305 nanoclay. Spectrum 3 demonstrates the absorption bands almost identical to the original composition both in terms of a wavenumber value and a peak intensity. In spectrum 2 (IC No. 1 without a nanoclay admixture), we can note a decrease in the absorption peaks of all three main components - APP, MA, and PE. This situation is evidence of the washing out of the main components of IC under the conditions of humidity of $80 \%$. In turn, the data on spectra 4 and 5 demonstrate a significant change in the formulation of the original composition of IC No. 1 after immersion in water for 15 days, both in the presence of nanoclay (spectrum 5 , Fig. 7) and in its absence (spectrum 4, Fig. 7). The main difference between IC No. 1 without an admixture of nanoclay (spectrum 4, Fig. 7) is the presence of PE in the form of traces (the band is $3,321 \mathrm{~cm}^{-1}$ ), as well as the EVA polymer (a slightly pronounced peak at $1,728 \mathrm{~cm}^{-1}$ ). The most likely way to reduce the polymer content is its acid hydrolysis under the action of protons of phosphoric acid and water. For IC No. 1 with an admixture of Garamite 7305 (spectrum 5, Fig. 7) the bands of hydroxyl groups of PE and a carbonyl group of EVA are expressed more clearly and, in conjunction with the values of the swell coefficient $K$ (Table 2, 15 days), indicate the positive effect of nanoclay admixtures on the preservation of the integrity of an intumescent coating even under the conditions of prolonged immersion in water.

The data reported here allow us to argue that the addition of nanoclays to the composition of intumescent coatings prevents changes in the chemical composition of samples under the influence of moisture. Dissolution of the fire protection agent begins with migration from the coating of PE, APP, and polymer degradation. In IC, in the presence of nanoclay, these processes occur more slowly due to the action of the barrier effect. 
Our results could be used in the development of waterproof fire-retardant nano-coatings for steel structures based on the IC with an $\mathrm{APP} / \mathrm{MA} / \mathrm{PE} /$ polymer composition. At the same time, to increase the water-resistance of the coating without reducing its fire-protective efficiency, an individual choice of nanoclay is extremely important, taking into consideration the dependence of the swell coefficient of a particular IC on the nature of the nanoclay used and its quantity. There is a high probability of a conflict between the intensity of swelling and the magnitude of the barrier effect. In case the second factor prevails, the mechanism of action of an intumescent coating could be completely depressed.

The further area of research into the impact of nanoclays on the fireproof and operational characteristics of reactive fire protection means is the accumulation of experimental material. Of particular interest are the results on the variation in both the structure of nanoclay and, first of all, in the nature of the polymer component of IC, as well as the conditions of climate tests. The availability of such studies would form the basis for systematization and generalization in order to design environmentally resistant intumescent coatings.

\section{Conclusions}

1. We have determined the influence of the structure and quantity of nanoclays as the admixtures to the intumescent system of ammonium polyphosphate/melamine/pentaerythritol/polymer (ethylene vinyl acetate or styrene acrylate) on ensuring maximum fire protection efficiency. It has been shown that for intumescent systems based on EVA, the admixtures of unmodified and organically-modified bentonites in the amount of up to $2 \%$, as well as synthetic hectorites in the amount of up to $0.6 \%$, are effective. For SA-based intumescent systems, organically-modified bentonite clays at a concentration of up to $0.3 \%$ are the best.

2. Immersing intumescent coatings in water for a period of more than 2 days leads to a significant decrease in the swell coefficient, regardless of the content of the nano admixture. At the same time, the half-decay period of coatings without nanoclay, calculated on the basis of solubility constant in water, is 0.5 days, and, for coatings that have the admixtures of organically-modified nanoclays, it increases to 2 days. The most effective admixtures in the class of nanoclays to intumescent compositions, providing for the maximum indicators of fire and water resistance, are organically-modified montmorillonites.

3. An intumescent coating during operation under the conditions of $80 \%$ humidity begins to lose its fireproof efficiency after 200 days. The loss of fire resistance by the coating occurs due to the leaching of pentaerythritol, ammonium polyphosphate, and polymer degradation by hydrolysis. Operating the coating under these conditions over 800 days reduces the fireproof properties of the fire protection agent by an average of $10 \%$. Admixtures to the investigated system of the organically-modified nanoclays of a montmorillonite series with a high degree of exfoliation create a barrier effect that preserves the chemical composition of the intumescent coating. In this case, within 800 days under the conditions of $80 \%$ of air humidity, the fireproof properties of the coating remain unchanged or reduced to $5 \%$. The proposed approaches to using nanoclays in order to increase fire-protective efficiency and operational properties of intumescent coatings could be used as promising in the development of durable reactive-type fire protection coatings.

\section{References}

1. Yasir, M., Ahmad, F., Yusoff, P. S. M. M., Ullah, S., Jimenez, M. (2019). Latest trends for structural steel protection by using intumescent fire protective coatings: a review. Surface Engineering, 36 (4), 334-363. doi: https://doi.org/10.1080/02670844.2019.1636536

2. Puri, R. G., Khanna, A. S. (2016). Intumescent coatings: A review on recent progress. Journal of Coatings Technology and Research, 14 (1), 1-20. doi: https://doi.org/10.1007/s11998-016-9815-3

3. Jimenez, M., Bellayer, S., Naik, A., Bachelet, P., Duquesne, S., Bourbigot, S. (2016). Topcoats versus Durability of an Intumescent Coating. Industrial \& Engineering Chemistry Research, 55 (36), 9625-9632. doi: https://doi.org/10.1021/acs.iecr.6b02484

4. Ji, W., hua, S. W., Miao, Z., Zhen, C. (2014). Study and Prediction for the Fire Resistance of Acid Corroded Intumescent Coating. Procedia Engineering, 84, 524-534. doi: https://doi.org/10.1016/j.proeng.2014.10.464

5. Mačiulaitis, R., Grigonis, M., Malaiškienè, J., Lipinskas, D. (2018). Peculiarities of destruction mechanism of polymeric intumescent fire protective coatings. Journal of Civil Engineering and Management, 24 (2), 93-105. doi: https://doi.org/10.3846/jcem.2018.447

6. Bilotta, A., de Silva, D., Nigro, E. (2016). Tests on intumescent paints for fire protection of existing steel structures. Construction and Building Materials, 121, 410-422. doi: https://doi.org/10.1016/j.conbuildmat.2016.05.144

7. Aziz, H., Ahmad, F. (2016). Effects from nano-titanium oxide on the thermal resistance of an intumescent fire retardant coating for structural applications. Progress in Organic Coatings, 101, 431-439. doi: https://doi.org/10.1016/j.porgcoat.2016.09.017

8. Chuang, C.-S., Sheen, H.-J. (2019). Effects of added nanoclay for styrene-acrylic resin on intumescent fire retardancy and CO/ $\mathrm{CO}_{2}$ emission. Journal of Coatings Technology and Research, 17 (1), 115-125. doi: https://doi.org/10.1007/s11998-019-00246-x

9. Zulkurnain, E. S., Ahmad, F., Gillani, Q. F. (2016). Effects of nano-sized boron nitride (BN) reinforcement in expandable graphite based in-tumescent fire retardant coating. IOP Conference Series: Materials Science and Engineering, 146, 012037. doi: https:// doi.org/10.1088/1757-899x/146/1/012037

10. Nour El-Dein, A., El-Saeed, M. A., Abo-Elenien, O. M. (2017). Fire-Resistivity Personification Of Waterborne Intumescent FlameRetardant Nano-Coatings For Steel Structures: Application. IJERA, 7 (8), 1-12. Available at: https:/journals.indexcopernicus.com/ api/file/viewByFileId/383128.pdf

11. Anees, S. M., Dasari, A. (2018). A review on the environmental durability of intumescent coatings for steels. Journal of Materials Science, 53 (1), 124-145. doi: https://doi.org/10.1007/s10853-017-1500-0

12. Wang, J., Zhao, M. (2020). Study on the effects of aging by accelerated weathering on the intumescent fire retardant coating for steel elements. Engineering Failure Analysis, 118, 104920. doi: https://doi.org/10.1016/j.engfailanal.2020.104920 
13. Wang, L. L., Wang, Y. C., Li, G. Q., Zhang, Q. Q. (2020). An experimental study of the effects of topcoat on aging and fire protection properties of intumescent coatings for steel elements. Fire Safety Journal, 111, 102931. doi: https://doi.org/10.1016/ j.firesaf.2019.102931

14. Vakhitova, L. N. (2019). Fire retardant nanocoating for wood protection. Nanotechnology in Eco-Efficient Construction, 361-391. doi: https://doi.org/10.1016/b978-0-08-102641-0.00016-5

15. Gaur, S., Khanna, A. S. (2015). Functional Coatings by Incorporating Nanoparticles. Nano Res. Appl., 1 (1), 1-9. Available at: https://nanotechnology.imedpub.com/functional-coatings-by-incorporating-nanoparticles.php?aid=7651

16. Fallah, F., Khorasani, M., Ebrahimi, M. (2017). Improving the mechanical properties of waterborne nitrocellulose coating using nano-silica particles. Progress in Organic Coatings, 109, 110-116. doi: https://doi.org/10.1016/j.porgcoat.2017.04.016

17. Zybina, O., Gravit, M., Stein, Y. (2017). Influence of carbon additives on operational properties of the intumescent coatings for the fire protection of building constructions. IOP Conference Series: Earth and Environmental Science, 90, 012227. doi: https:// doi.org/10.1088/1755-1315/90/1/012227

18. Xu, Z., Zhou, H., Yan, L., Jia, H. (2019). Comparative study of the fire protection performance and thermal stability of intumescent fire-retardant coatings filled with three types of clay nano fillers. Fire and Materials, 44 (1), 112-120. doi: https://doi.org/10.1002/ fam. 2780

19. Wang, Z., Han, E., Ke, W. (2006). Fire-resistant effect of nanoclay on intumescent nanocomposite coatings. Journal of Applied Polymer Science, 103 (3), 1681-1689. doi: https://doi.org/10.1002/app.25096

20. EAD 350402-00-1106. Reactive coatings for fire protection of steel elements (2017). EOTA, 32. Available at: https://www.kiwa. $\mathrm{com} / \mathrm{nl} / \mathrm{nl} /$ service/brandwerende-producten-etag-018-ead/ead-350402-00-1106-reactive-coatings-for-fire-protection-of-steelelements2.pdf/

21. Kwang Yin, J. J., Yew, M. C., Yew, M. K., Saw, L. H. (2019). Preparation of Intumescent Fire Protective Coating for Fire Rated Timber Door. Coatings, 9 (11), 738. doi: https://doi.org/10.3390/coatings9110738

22. Pimenta, J. T., Gonçalves, C., Hiliou, L., Coelho, J. F. J., Magalh es, F. D. (2015). Effect of binder on performance of intumescent coatings. Journal of Coatings Technology and Research, 13 (2), 227-238. doi: https://doi.org/10.1007/s11998-015-9737-5

23. Vakhitova, L., Bessarabov, V., Taran, N., Redko, A., Anishchenko, V., Zagoriy, G., Popov, A. (2019). Definition of the thermal and fireprotective properties of ethylene-vinyl acetate copolymer nanocomposites. Eastern-European Journal of Enterprise Technologies, 1 (6 (97)), 13-20. doi: https://doi.org/10.15587/1729-4061.2019.154676

24. Vakhitova, L., Taran, N., Kalafat, K., Pridatko, S., Prudchenko, A. (2019). Influence of styrolacrylate nanocomposites on fire protective efficiency of intumescent type reactive coating. Journal of Donetsk Mining Institute, 1 (44), 87-99. doi: https:// doi.org/10.31474/1999-981x-2019-1-87-99 